\title{
Fatty acid composition of milk from mothers giving birth at extremely low gestation in Sweden
}

\author{
Ulrika Sjöbom $^{1}$, Osman Cismaan ${ }^{1}$, Ingrid Hansen-Pupp ${ }^{2}$, Dirk Wackernagel ${ }^{3}$ (D), Karin Sävman ${ }^{4,5}$, \\ Ann Hellström ${ }^{1}\left(\right.$ ) and Anders K. Nilsson ${ }^{1}{ }^{1}$ (i) \\ ${ }^{1}$ Section for Opthalmology, Department of Clinical Neuroscience, Institute of Neuroscience and Physiology, Sahlgrenska \\ Academy, University of Gothenburg, Gothenburg, Sweden, ${ }^{2}$ Department of Clinical Sciences Lund, Pediatrics, Skåne University \\ Hospital, Lund University, Lund, Sweden, ${ }^{3}$ Department of Neonatology, Karolinska University Hospital and Institute, Astrid \\ Lindgren Children's Hospital, Stockholm, Sweden, ${ }^{4}$ Department of Pediatrics, Institute of Clinical Sciences, Sahlgrenska \\ Academy, University of Gothenburg, Gothenburg, Sweden, and ${ }^{5}$ Region Västra Götaland, Department of Neonatology, \\ The Queen Silvia Children's Hospital, Sahlgrenska University Hospital, Gothenburg, Sweden \\ *Corresponding author. Email: anders.k.nilsson@gu.se
}

(Received 07 December 2021; Revised 03 February 2022; Accepted 05 February 2022)

\begin{abstract}
Preterm infants show postnatal deficits of long-chain polyunsaturated fatty acids (LCPUFAs) which are essential for adequate growth and neurodevelopment. Human milk is a primary source of fatty acids (FAs) for the preterm infant, and therefore, knowledge about milk FA levels is required to design appropriate supplementation strategies. Here, we expanded on our previous study (Nilsson et al., 2018, Acta Paediatrica, $107,1020-1027)$ determining FA composition in milk obtained from mothers of extremely low gestational age ( $<28$ weeks) infants on three occasions during lactation. There was a clear difference in FA composition in milk collected at Day 7 and milk collected at postmenstrual weeks (PMW) 32 or PMW 40. Notably, the proportion of LCPUFAs was low and declined significantly during milk maturation. These results strengthen previous data that the content of FAs required by the preterm infant is not supplied in sufficient amounts when the mother's own milk is the sole source of these essential nutrients.
\end{abstract}

Key words: docosahexaenoic acid; expressed milk; human milk; long-chain polyunsaturated fatty acids; preterm infant

\section{Introduction}

Fetal growth and development depend on the selective placental transport of long-chain polyunsaturated fatty acids (LCPUFAs). After premature birth, this transfer is disrupted and the infant becomes reliant on fatty acids (FAs) provided from intravenous lipid emulsions, human milk, and/or preterm formula. Accumulating evidence indicates that infants born at extremely low gestation obtain insufficient amounts of LCPUFAs to fulfill their nutritional needs in the perinatal period (Robinson \& Martin, 2017), particularly the omega-3 FA docosahexaenoic acid (DHA, 22:6 n-3) and the omega-6 FA arachidonic acid (AA, 20:4 n-6; Hellström et al., 2021).

Human milk is considered the best nutrition for the preterm infant (Hård et al., 2019), providing FAs to support energy demands as well as omega-3 and omega- 6 type LCPUFAs. However, mother's own milk, donor human milk, or formula alone do not supply the necessary quantities of LCPUFA required for the rapidly growing infant (Klevebro et al., 2019). Maternal milk LCPUFAs content must be considered when the best clinical supplementation strategies in this fragile group of infants are investigated. 


\section{Objective}

We have previously reported on the FA profiles of milk from women delivering at extremely low gestation and how the FA composition changes during three stages of lactation: at 1 week after delivery (Day 7, transitional milk), and at postmenstrual weeks 32 and 40 (PMW 32 and PMW 40, mature milk; Nilsson et al., 2018). This study aimed to expand on these data in a larger up-dated cohort of women recruited at three centers in Sweden.

\section{Methods}

This study is part of the Mega Donna Mega trial (ClinicalTrials.gov Identifier: NCT03201588; Hellström et al., 2021). The trial protocol was approved by the Regional ethics review board in Gothenburg. Informed consent was obtained from all mothers included in the study. The authors assert that all procedures contributing to this work comply with the ethical standards of the relevant national and institutional committees on human experimentation and with the Helsinki Declaration of 1975, as revised in 2008.

The study was performed at three Swedish centers from December 15, 2016 to December 15, 2019. Expressed milk was collected from 151 women who had given birth to 159 infants. Mean (standard deviation [SD]) weeks of gestation at delivery was 25.6 (1.4). Milk (125 $\mu$ l) FAs were converted to fatty acid methyl esters by direct acid transesterification (Cruz-Hernandez et al., 2013) and analyzed by gas chromatography-mass spectrometry (GC-MS; Nilsson et al., 2018). GC oven parameters were as follow: $100^{\circ} \mathrm{C}$ for $2 \mathrm{~min}, 15^{\circ} \mathrm{C} / \mathrm{min}$ to $150^{\circ} \mathrm{C}$ for $1 \mathrm{~min}, 2.5^{\circ} \mathrm{C} / \mathrm{min}$ to $214^{\circ} \mathrm{C}$ for $1 \mathrm{~min}$, then $70^{\circ} \mathrm{C} / \mathrm{min}$ to $240^{\circ} \mathrm{C}$ for $2 \mathrm{~min}$. One microliter of sample was injected in a 10:1 split ratio. The between analysis coefficient of variation for AA and DHA for the method was $9.6 \%$ and $11.3 \%$, and within batch $4.0 \%$ and $6.7 \%$, respectively. Statistical analyses were performed in SIMCA 17 (Umetrics AB, Umeå, Sweden) and IBM SPSS Statistics version 26 (IBM Corp, Armonk NY).

\section{Results}

Milk samples collected at Day 7 versus at PMW 32 and 40 were separated in the first component in a principal component analysis (PCA, Figure 1a). This separation was largely driven by composition differences in LCPUFAs, long-chain saturated FAs, and long-chain monounsaturated FAs, being generally higher in milk from Day 7 (Figure $1 \mathrm{~b}$ and Table 1). DHA and AA decreased from median (Q1-Q3) $0.35(0.28-0.46)$ and $0.49(0.41-0.61)$ to $0.22(0.17-0.31)$ and $0.34(0.28-0.40)$ mol\% between

A

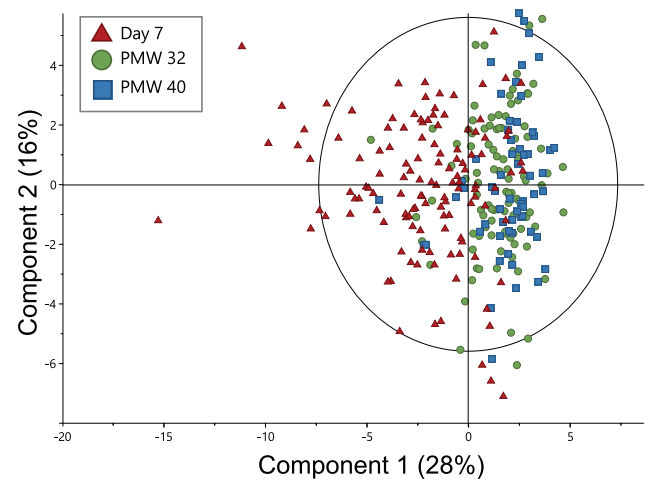

B

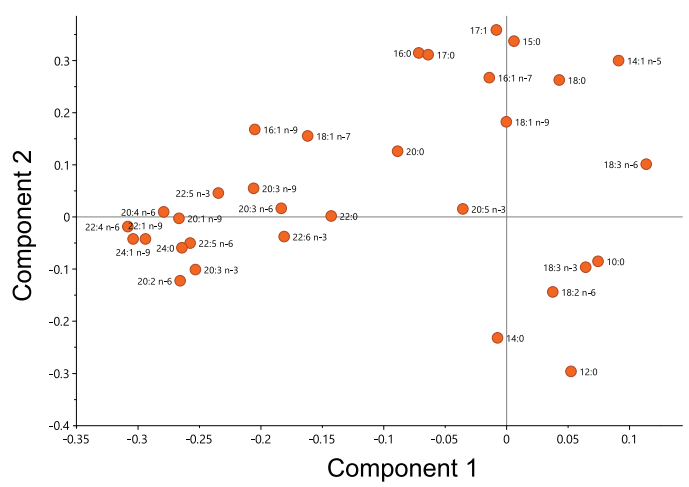

Figure 1. Principal component analysis (PCA) based on the fatty acid profiles of milk samples collected at Day 7 , at postmenstrual week 32 (PMW 32), and PMW 40 (total $n=288$ ). (a) PCA scatter plot colored according to sampling occasion and (b) the corresponding loading plot. The ellipse in (a) shows Hotelling's $T^{2}$ ( $95 \%$ confidence limit). PCA model: six components, $R^{2} X=0.76$ and $Q^{2}=0.49$. 
Table 1. Proportions of fatty acids (FAs) in milk samples collected on three occasions during lactation

\begin{tabular}{|c|c|c|c|c|}
\hline Common name & Lipid name & Day $7(n=124)$ & $\begin{array}{c}\text { Postmenstrual } \\
\text { week } 32(n=103)\end{array}$ & $\begin{array}{c}\text { Postmenstrual } \\
\text { week } 40(n=61)\end{array}$ \\
\hline \multicolumn{5}{|l|}{ Saturated FA (SFA) } \\
\hline Capric acid & $10: 0$ & $2.44(1.86-2.84)^{a, b}$ & $2.59(2.24-3.07)$ & $2.51(2.09-2.83)$ \\
\hline Lauric acid & $12: 0$ & 10.15 (8.09-11.90) & 9.88 (7.57-11.99) & $9.24(7.39-11.87)$ \\
\hline Myristic acid & $14: 0$ & $9.88(8.23-11.99)^{a}$ & $8.57(7.25-10.97)$ & $8.84(7.39-11.28)$ \\
\hline Pentadecanoic acid & $15: 0$ & $0.32(0.27-0.36)$ & $0.31(0.24-0.38)$ & $0.29(0.24-0.42)$ \\
\hline Palmitic acid & $16: 0$ & $21.0(19.3-22.6)^{a, b}$ & $19.4(17.9-21.9)$ & $19.1(17.4-21.8)$ \\
\hline Margaric acid & $17: 0$ & $0.25(0.21-0.29)^{a}$ & $0.24(0.19-0.27)$ & $0.23(0.21-0.28)$ \\
\hline Stearic acid & $18: 0$ & $4.87(4.19-5.61)^{a, b}$ & $5.13(4.51-5.79)$ & $5.15(4.37-6.03)$ \\
\hline Arachidic acid & $20: 0$ & $0.13(0.11-0.15)^{b}$ & $0.12(0.11-0.14)$ & $0.12(0.10-0.13)$ \\
\hline Behenic acid & $22: 0$ & $0.062(0.053-0.070)^{a, b}$ & $0.055(0.050-0.065)$ & $0.057(0.051-0.063)$ \\
\hline \multirow[t]{2}{*}{ Lignoceric acid } & $24: 0$ & $0.083(0.067-0.098)^{a, b}$ & $0.051(0.043-0.062)$ & $0.042(0.034-0.051)$ \\
\hline & $\Sigma$ SFA & $49.6(45.6-53.1)$ & $47.4(44.2-52.4)$ & $47.2(42.0-51.5)$ \\
\hline \multicolumn{5}{|l|}{ Monounsaturated FA (MUFA) } \\
\hline Myristoleic acid & $14: 1 n-5$ & $0.24(0.20-0.30)^{a, b}$ & $0.26(0.21-0.35)$ & $0.25(0.19-0.33)$ \\
\hline Hexadecenoic acid $n-9$ & $16: 1 n-9$ & $0.42(0.37-0.50)^{a, b}$ & $0.35(0.31-0.40)$ & $0.36(0.32-0.41)$ \\
\hline Palmitoleic acid & $16: 1 n-7$ & $1.98(1.55-2.28)$ & $1.85(1.57-2.21)$ & $1.85(1.57-2.18)$ \\
\hline Heptadecenoic acid & $17: 1^{c}$ & $0.15(0.12-0.18)$ & $0.15(0.13-0.18)$ & $0.15(0.13-0.17)$ \\
\hline Oleic acid & $18: 1 n-9$ & $32.9(29.8-36.1)$ & $33.9(30.7-37.2)$ & $34.3(31.2-37.4)$ \\
\hline cis-Vaccenic acid & $18: 1 n-7$ & $1.68(1.47-1.89)^{a, b}$ & $1.54(1.33-1.71)$ & $1.54(1.36-1.67)$ \\
\hline Gondoic acid & $20: 1 n-9$ & $0.45(0.40-0.55)^{a, b}$ & $0.38(0.33-0.41)$ & $0.35(0.29-0.39)$ \\
\hline Erucic acid & $22: 1 n-9$ & $0.084(0.071-0.108)^{a, b}$ & $0.055(0.046-0.067)$ & $0.050(0.041-0.060)$ \\
\hline \multirow[t]{2}{*}{ Nervonic acid } & $24: 1 n-9$ & $0.14(0.11-0.17)^{a, b}$ & $0.06(0.05-0.08)$ & $0.05(0.04-0.06)$ \\
\hline & $\Sigma$ MUFA & $38.3(34.7-41.8)$ & $38.8(35.5-42.6)$ & $39.2(35.6-42.0)$ \\
\hline \multicolumn{5}{|l|}{ Polyunsaturated FA n-9 } \\
\hline Mead acid & $20: 3 n-9$ & $0.014(0.011-0.016)^{a, b}$ & $0.011(0.010-0.013)$ & $0.011(0.009-0.013)$ \\
\hline \multicolumn{5}{|c|}{ Polyunsaturated FA n-6 (PUFA $n-6$ ) } \\
\hline Linoleic acid & $18: 2 n-6$ & $8.47(7.37-9.86)^{a, b}$ & $9.14(8.21-10.94)$ & $9.72(8.46-12.60)$ \\
\hline$\gamma$-linolenic acid & $18: 3 n-6$ & $0.058(0.039-0.088)^{a, b}$ & $0.080(0.059-0.106)$ & $0.088(0.057-0.113)$ \\
\hline Dihomolinoleic acid & $20: 2 n-6$ & $0.26(0.20-0.33)^{a, b}$ & $0.17(0.14-0.21)$ & $0.16(0.12-0.17)$ \\
\hline Dihomo- $\gamma$-linolenic acid & $20: 3 n-6$ & $0.44(0.36-0.55)^{a, b}$ & $0.30(0.25-0.36)$ & $0.25(0.21-0.32)$ \\
\hline Arachidonic acid (AA) & $20: 4 n-6$ & $0.49(0.42-0.61)^{a, b}$ & $0.34(0.29-0.41)$ & $0.33(0.28-0.39)$ \\
\hline Adrenic acid & $22: 4 n-6$ & $0.11(0.07-0.15)^{a, b}$ & $0.05(0.04-0.06)$ & $0.04(0.04-0.06)$ \\
\hline \multirow[t]{3}{*}{ Docosapentaenoic acid $n-6$} & $22: 5 n-6$ & $0.025(0.019-0.032)^{a, b}$ & $0.015(0.012-0.020)$ & $0.013(0.011-0.019)$ \\
\hline & $\Sigma$ PUFA $n-6$ & $9.93(8.84-11.34)$ & $10.24(9.11-11.98)$ & $10.64(9.27-13.45)$ \\
\hline & $\begin{array}{c}\Sigma \text { LCPUFA } n- \\
6(\geq \mathrm{C} 20)\end{array}$ & $1.40(1.16-1.63)^{a, b}$ & $0.90(0.75-1.05)$ & $0.80(0.70-0.92)$ \\
\hline
\end{tabular}


Table 1. Continued

\begin{tabular}{|c|c|c|c|c|}
\hline Common name & Lipid name & Day $7(n=124)$ & $\begin{array}{c}\text { Postmenstrual } \\
\text { week } 32(n=103)\end{array}$ & $\begin{array}{c}\text { Postmenstrual } \\
\text { week } 40(n=61)\end{array}$ \\
\hline \multicolumn{5}{|c|}{ Polyunsaturated FA $n-3$ (PUFA $n-3$ ) } \\
\hline$\alpha$-linolenic acid & $18: 3 n-3$ & $1.30(1.04-1.54)^{a}$ & $1.62(1.21-1.97)$ & $1.77(1.08-2.04)$ \\
\hline Eicosatrienoic acid $n-3$ & $20: 3 n-3$ & $0.079(0.063-0.108)^{a, b}$ & $0.054(0.045-0.067)$ & $0.044(0.035-0.057)$ \\
\hline $\begin{array}{l}\text { Eicosapentaenoic acid } \\
\text { (EPA) }\end{array}$ & $20: 5 n-3$ & $0.065(0.052-0.083)$ & $0.068(0.048-0.095)$ & $0.069(0.047-0.106)$ \\
\hline Docosapentaenoic acid $n-3$ & $22: 5 n-3$ & $0.14(0.12-0.20)^{a, b}$ & $0.12(0.10-0.14)$ & $0.12(0.10-0.15)$ \\
\hline \multirow{3}{*}{$\begin{array}{l}\text { Docosahexaenoic acid } \\
(\mathrm{DHA})\end{array}$} & $22: 6 n-3$ & $0.36(0.29-0.47)^{\mathrm{a}, \mathrm{b}}$ & $0.22(0.17-0.32)$ & $0.22(0.18-0.32)$ \\
\hline & $\Sigma$ PUFA $n-3$ & $2.02(1.68-2.36)$ & $2.09(1.66-2.62)$ & $2.31(1.56-2.57)$ \\
\hline & $\begin{array}{c}\Sigma \text { LCPUFA } n- \\
\quad 3(\geq \mathrm{C} 20)\end{array}$ & $0.64(0.55-0.84)^{a, b}$ & $0.47(0.38-0.61)$ & $0.45(0.37-0.62)$ \\
\hline
\end{tabular}

Data are expressed as the molar percent (mol\%) of all analyzed fatty acids and presented as median (Q1-Q3). Minimum/maximum days for sample collection were $6 / 12$ for Day 7 samples, 29/68 for postmenstrual week 32 samples, and 69/128 for postmenstrual week 40 samples.

${ }^{a}$ Significantly different between postnatal day 7 and PMA 32 weeks $(n=78)$ according to the Wilcoxon signed-rank test $(p<.05)$.

${ }^{\mathrm{b}}$ Significantly different between postnatal day 7 and PMA 40 weeks $(n=44)$ according to the Wilcoxon signed-rank test $(p<.05)$.

'Likely representing the cis- $\Delta^{9}$ 17:1 isomer (17:1 n-8) (Precht \& Molkentin, 2000).

Day 7 and PMW 32. This change corresponded to a 30\% reduction in AA and 37\% reduction in DHA from Day 7 to PMW 32 (Supplementary Table S1). Levels of DHA and AA were similar at PMW 32 and 40. The fraction of the $n-3$ LCPUFA eicosapentaenoic acid (EPA, 20:5n-3) remained stable across all time points. FAs increasing in proportion during the progress of milk maturation included linoleic acid (18:2 $n$-6), $\gamma$-linolenic acid (18:3n-6), and $\alpha$-linolenic acid (18:3n-3). Although samples separated according to milk maturation stage in the PCA, they were not well grouped, displaying a large variation in FA milk composition between the lactating women.

\section{Discussion}

This study confirms our previous results that the content of LCPUFAs is low in milk from Swedish mothers of extremely low gestational age infants and that levels decline significantly during milk maturation (Nilsson et al., 2018). The proportions of DHA and AA in transitional and mature milk were similar in this cohort as reported for preterm milk in a recent meta-analysis (Floris et al., 2020). There was a high heterogeneity in milk FA composition between the lactating mothers, likely reflecting differences in diet, genetic background, and lifestyle choices, among other factors (Koletzko, 2016).

\section{Conclusions}

Extremely preterm infants miss the maternal transfer of LCPUFAs during the third trimester and are thus born with low endogenous deposits. The low content of LCPUFAs in mother's own milk may aggravate the deficit with potential consequences for the preterm infant's growth and development. Supplementation strategies for infants born extremely preterm based on the known intake of LCPUFA in milk and other sources and the calculated needs of the infant are warranted. The data presented here may be used in decision-making when such supplementation strategies are designed.

Acknowledgments. The authors thank all participating mothers and their families who made this study possible. The authors also thank the nursing, medical, and research staff at the neonatal units in Gothenburg, Lund and Stockholm for their excellent work. 
Supplementary Materials. To view supplementary material for this article, please visit http://doi.org/10.1017/exp.2022.4.

Data availability statement. The datasets used and analyzed during the current study are available from the corresponding author on reasonable request.

Funding statement. This work was primarily supported by the Swedish Medical Research Council (2015-00810). We also acknowledge the support from the Swedish Medical Research Council (2016-01131), the Gothenburg Medical Society, De Blindas Vänner, Government grants under the ALF agreements (ALFGBG-717971, ALFGBG-812951), and the Wallenberg Clinical Scholars.

Conflict of interest. The authors declare that they have no conflict of interest.

Authorship contributions. A.K.N. and A.H. conceived and designed the study. I.H.P., D.W., and K.S. were involved in sample collection. U.S. and O.C. prepared samples for analysis and A.K.N. conducted mass spectrometry data gathering. A.K.N. performed statistical analyses. A.K.N. drafted the manuscript. All authors critically revised and approved the final manuscript.

\section{References}

Cruz-Hernandez, C., Goeuriot, S., Giuffrida, F., Thakkar, S. K., \& Destaillats, F. (2013). Direct quantification of fatty acids in human milk by gas chromatography. Journal of Chromatography A, 1284, 174-179. https://doi.org/10.1016/j. chroma.2013.01.094

Floris, L. M., Stahl, B., Abrahamse-Berkeveld, M., \& Teller, I. C. (2020). Human milk fatty acid profile across lactational stages after term and preterm delivery: A pooled data analysis. Prostaglandins, Leukotrienes, and Essential Fatty Acids, 156, 102023. https://doi.org/10.1016/j.plefa.2019.102023

Hård, A. L., Nilsson, A. K., Lund, A. M., Hansen-Pupp, I., Smith, L. E. H., \& Hellström, A. (2019). Review shows that donor milk does not promote the growth and development of preterm infants as well as maternal milk. Acta Paediatrica, 108, 998-1007. https://doi.org/10.1111/apa.14702

Hellström, A., Nilsson, A. K., Wackernagel, D., Pivodic, A., Vanpee, M., Sjöbom, U., Hellgren, G., Hallberg, B., Domellöf, M., Klevebro, S., Hellström, W., Andersson, M., Lund, A. M., Löfqvist, C., Elfvin, A., Sävman, K., Hansen-Pupp, I., Hård, A. L., Smith, L. E. H., \& Ley, D. (2021). Effect of Enteral Lipid Supplement on Severe Retinopathy of Prematurity: A Randomized Clinical Trial. JAMA Pediatr, 175(4), 359-367. https://doi.org/10.1001/jamapediatrics.2020.5653

Klevebro, S., Juul, S. E., \& Wood, T. R. (2019). A more comprehensive approach to the neuroprotective potential of long-chain polyunsaturated fatty acids in preterm infants is needed-should we consider maternal diet and the n-6:n-3 fatty acid ratio? Frontiers in Pediatrics, 7, 533. https://doi.org/10.3389/fped.2019.00533

Koletzko, B. (2016). Human milk lipids. Annals of Nutrition and Metabolism, 69, 27-40. https://doi.org/10.1159/000452819

Nilsson, A. K., Löfqvist, C., Najm, S., Hellgren, G., Sävman, K., Andersson, M. X., Smith, L. E. H., \& Hellström, A. (2018). Long-chain polyunsaturated fatty acids decline rapidly in milk from mothers delivering extremely preterm indicating the need for supplementation. Acta Paediatrica, 107(6), 1020-1027. https://doi.org/10.1111/apa.14275

Precht, D., \& Molkentin, J. (2000). Identification and quantitation of cis/trans C16:1 and C17:1 fatty acid positional isomers in German human milk lipids by thin-layer chromatography and gas chromatography/mass spectrometry. European Journal of Lipid Science and Technology, 102, 102-113. https://doi.org/10.1002/(SICI)1438-9312(200002)102:2<102::AIDEJLT102>3.0.CO;2-C

Robinson, D. T., \& Martin, C. R. (2017). Fatty acid requirements for the preterm infant. Seminars in Fetal \& Neonatal Medicine, 22, 8-14. https://doi.org/10.1016/j.siny.2016.08.009

Cite this article: Sjöbom U, Cismaan O, Hansen-Pupp I, Wackernagel D, Sävman K, Hellström A, Nilsson AK (2022). Fatty acid composition of milk from mothers giving birth at extremely low gestation in Sweden. Experimental Results, 3, e9, 1-9. https://doi.org/10.1017/exp.2022.4 


\section{Peer Reviews}

\section{Reviewing editor: Dr. Francisco Javier Alarcón López}

Universidad de Almeria, Almeria, Spain, 04120

This article has been accepted because it is deemed to be scientifically sound, has the correct controls, has appropriate methodology and is statistically valid, and has been sent for additional statistical evaluation and met required revisions.

\section{doi:10.1017/exp.2022.4.pr1}

\section{Review 1: Fatty acid composition of milk from mothers giving birth at extremely low gestation in Sweden}

Reviewer: Dr. Ana Jiménez-Carvelo

Date of review: 29 January 2022

(C) The Author(s), 2022. Published by Cambridge University Press. This is an Open Access article, distributed under the terms of the Creative Commons Attribution licence (http://creativecommons.org/licenses/by/4.0), which permits unrestricted re-use, distribution and reproduction, provided the original article is properly cited.

Conflict of interest statement. Reviewer declares none

\section{Comment}

Comments to the Author: The authors report the extension of data from a previous study on the importance of the presence of polyunsaturated fatty acids in breast milk for infant development.

Although the study is interesting, it does not contribute anything new or innovative to the previously published study. This study only provides more data than the previously published study.

Furthermore, the authors base their results on exploratory data analysis (PCA), but the graph shown in figure 2 does not show clear trends in the grouping of the three types of samples analysed according to fatty acid composition. In fact, there is only a slight tendency to group the samples classified as "day 7 " with negative scores for component 1 and the remaining two with positive scores, as the authors state in the results section.

For this reason, I recommend not to publish this study, as a more complete study is needed to correlate the authors' hypothesis.

\section{Score Card}

Presentation

2.9

Is the article written in clear and proper English? (30\%)

Is the data presented in the most useful manner? (40\%)

Does the paper cite relevant and related articles appropriately? (30\%)

\section{Context}


Analysis

Are the limitations of the experiment as well as the contributions of the experiment clearly outlined? (20\%) 


\section{Review 2: Fatty acid composition of milk from mothers giving birth at extremely low gestation in Sweden}

Reviewer: Dr. M.I. Sáez

Universidad de Almería, Biología y Geología, Almeria, Spain, 04120

Date of review: 26 January 2022

(C) The Author(s), 2022. Published by Cambridge University Press. This is an Open Access article, distributed under the terms of the Creative Commons Attribution licence (http://creativecommons.org/licenses/by/4.0), which permits unrestricted re-use, distribution and reproduction, provided the original article is properly cited.

Conflict of interest statement. Reviewer declares none.

\section{Comment}

Comments to the Author: In this piece of research, the authors broached a short note about the quality in term of fatty acids profile of milk from mothers giving birth at extremely low gestation in Sweden. This is hot topic because every year around 15 million babies are born before reaching term, that is, more than one in ten births.

However, there are some general concerns listed below that should be addressed in order to improve it.

-Why have these sampling points been taken? It would have been interesting to take samples at intermediate points between 7 days and 32 weeks ( 8 months). In my opinion, the measurement at 8 and 16 weeks would give us interesting data.

-It would have been interesting to include a control of breast milk from mothers who gave birth at term, to see these variations that are discussed.

-Figure 1 does not provide much information. The measurement parameters can be incorporated in the material and methods section.

-Perhaps it would have been interesting to include a table showing the differences in the percentage of fatty acids at the different sampling points. Although this is a suggestion only.

-In pag 4, as for linoleic acid, specify the nomenclature of the fatty acids DHA and AA.

\section{Score Card}

Presentation

3.6

Is the article written in clear and proper English? (30\%)

Is the data presented in the most useful manner? (40\%)

Does the paper cite relevant and related articles appropriately? (30\%)

Context

Does the abstract correctly embody the content of the article? (25\%)

Does the introduction give appropriate context? (25\%)

Is the objective of the experiment clearly defined? (25\%) 
Analysis

Is the conclusion consistent with the results and discussion? (40\%)

Are the limitations of the experiment as well as the contributions of the experiment clearly outlined? (20\%) 